\title{
Qualitative and Quantitative Methods for Estimating the Library and Information Services
}

\author{
Natalya M. Natalinova*, Olga V. Galtseva ${ }^{\mathrm{a}}$, N. Xiu ${ }^{\mathrm{b}}$, Angelina M. Belan ${ }^{\mathrm{a}}$ \\ * Corresponding author: Nataliya Natalinova, natalinova@tpu.ru \\ ${ }^{a}$ National Research Tomsk Polytechnic University, 30, Lenina ave., Tomsk, Russia, 634050,natalinova@tpu.ru, +79069573127 \\ ${ }^{b}$ Beijing Jiaotong Daxue, No.3 Shangyuancun, Haidian District Beijing, China, 100044, xiu050210@gmail.com
}

\begin{abstract}
http://dx.doi.org/10.15405/epsbs.2017.01.65

An analysis of statistical data shows that attendance in the libraries falls every year, the demand of library information as the material carrier (for example books) is greatly reduced, but the information in electronic form is in demand, and every year the figures are growing significantly. This paper presents an estimation method for separate and complex indicators of the efficiency of library and information product and service rendering depending on various factors that determine service quality, timeliness and efficiency. A fuzzy logic system to transform the primary data was designed with the "Fuzzy Logic Toolbox" software using MATLAB. The methods to rank the studied factors by their importance and effect on the criteria of the efficiency of library and information product and service rendering are given. It is shown that the quality of library and information services plays an important role in development of society and influences the global socio-economic development and wellbeing. The research application contributes to the optimization of the library helps to more efficiently organize and plan their work, as well as the right to determine the direction of further investment. In addition, it enables the management of the library to identify factors that contribute to improving the efficiency of their businesses, to study the most urgent and important needs of the market library services, and also to establish the factors that currently are essential as for institutions, and for users and consumers.
\end{abstract}

(C) 2017 Published by Future Academy www.FutureAcademy.org.uk

Keywords: Library and information services; Quality management; Efficiency indicator; Fuzzy logic.

\section{Introduction}

The majority of enterprises in the service sector, libraries as an example, have to work in the conditions of fierce competition. Marketing research contributes to optimization of their activities, helps to efficiently organize and plan their work, and to identify the right areas for further investment. In addition, this research gives a chance to reveal the indicators, which improve the efficiency of 
eISSN: 2357-1330

Selection \& Peer-review under responsibility of the Conference Organization Committee

libraries, to study most actual and important market requirements to library services, and to set the indicators most important for users and consumers. The obtained quantitative dependences of various indicators of the efficiency on the influencing factors help the management of an organization to understand the market situation and to make their activities more expedient (Lau et al., 2015).

\section{Research method}

The method to present experts' opinions by means of fuzzy logic has been chosen as a method of estimating the quality indicators of library and information service rendering (Gong, \& Liu, 2010). The fuzzy logic frequently implies fuzzy inference systems used to control technical devices and processes (Campbell et al., 2016). The development and application of fuzzy inference systems include several steps; implementation of these steps is performed using the main rules of fuzzy logic (Madhusudhan, \& Singh, 2016). Information is fed into the fuzzy inference system input in the form of measured input variables. These variables correspond to actual variables of the control process (Rogovyh et al., 2015). The information from the fuzzy inference system output corresponds to the output variables and represents the operating variables of the control process. Fuzzy inference systems are used to convert input variables of the control process into output variables using fuzzy rules of productions. For this purpose, the fuzzy inference system needs to contain a data base of rules of fuzzy products and to realize fuzzy inference of the conclusions based on assumptions or conditions presented in the form of fuzzy linguistic statements (Zimmermann, 2001).

Figure 1 shows a functional scheme of fuzzy inference.

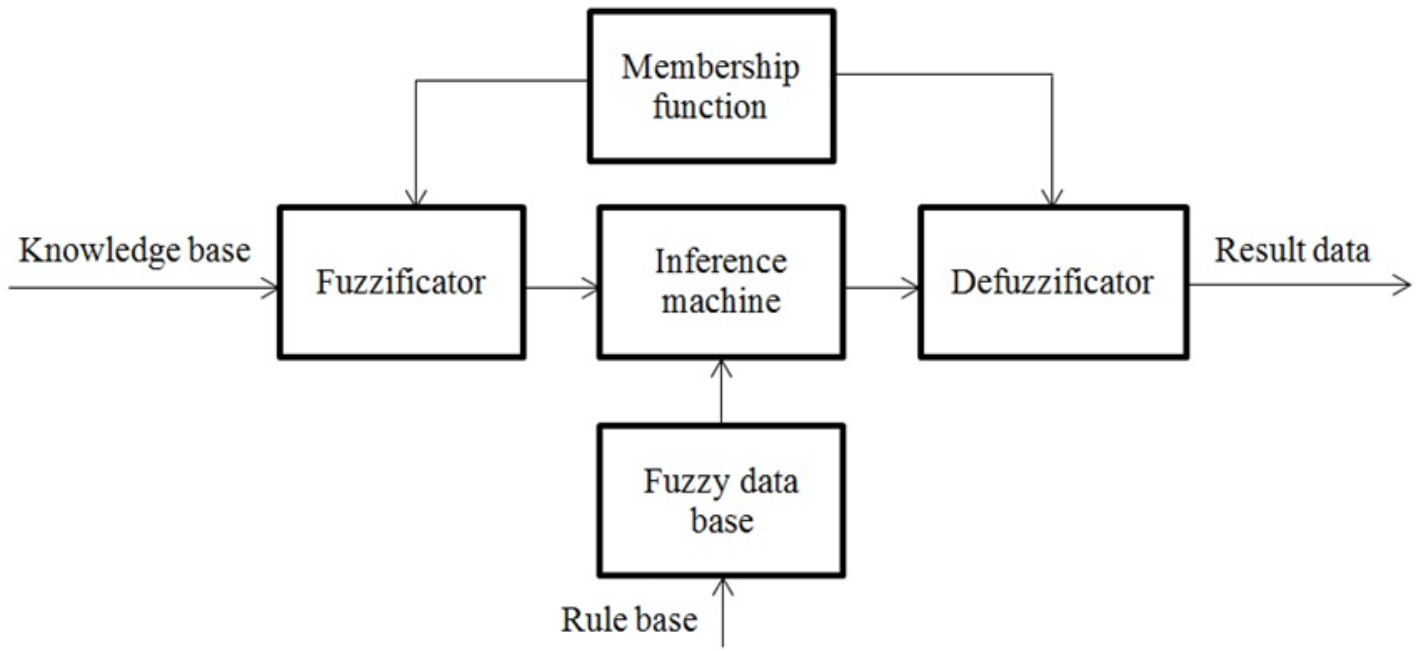

Fig. 1. Functional scheme of fuzzy inference process.

The fuzzy logic model allows obtaining a quantitative result based on the analysis of incomplete information on the research area and a convenient user interface, where the output data are similar to those obtained by human in their reasoning, approximation, uncertainty and subjectivity. In addition, increase in data processing speed is due to continuity of membership function.

The values of each input parameter and efficiency indicator are determined by the results obtained through questionnaires or $m$ experts' opinions processing (library users). Each of the experts can determine the value of each indicator $(Y)$. Thus, the $Y$ indicator can be estimated by the $m$-th expert in 
http://dx.doi.org/10.15405/epsbs.2017.01.65

eISSN: 2357-1330 / Corresponding Author: Nataliya Natalinova

Selection and peer-review under responsibility of the Organizing Committee of the conference

two ways: using the $Y^{m}$ assessment scale or by the corresponding $L_{j}^{m}(Y)$ linguistic variable. $Y^{m}$ estimate can be expressed as a whole and fractional number; it determines the $Y^{m}$ value, which correspond to the opinion of $m$-th expert. In case of measuring $L_{j}^{m}(Y)$ linguistic variable, the $y_{m}$ numeric value can be obtained in several ways: by method of the maximum, by method of gravity center and by the average value of the changed interval of the corresponding $y_{m}$ linguistic variable (Alhumaidi, 2015).

\section{Results and discussion}

A group of users were surveyed to calculate $F_{1}$ and $F_{2}$ efficiency indicators for a library. A survey was used to obtain primary information since the survey is the main method to obtain marketing information on service consumers and to evaluate various forms of service rendering. A questionnaire (expert evaluation sheet) was chosen as a research instrument to highlight the main indicators to obtain recommendations for management improvement (Natalinova et al., 2016).

Figure 2 shows an expert's evaluation sheet.

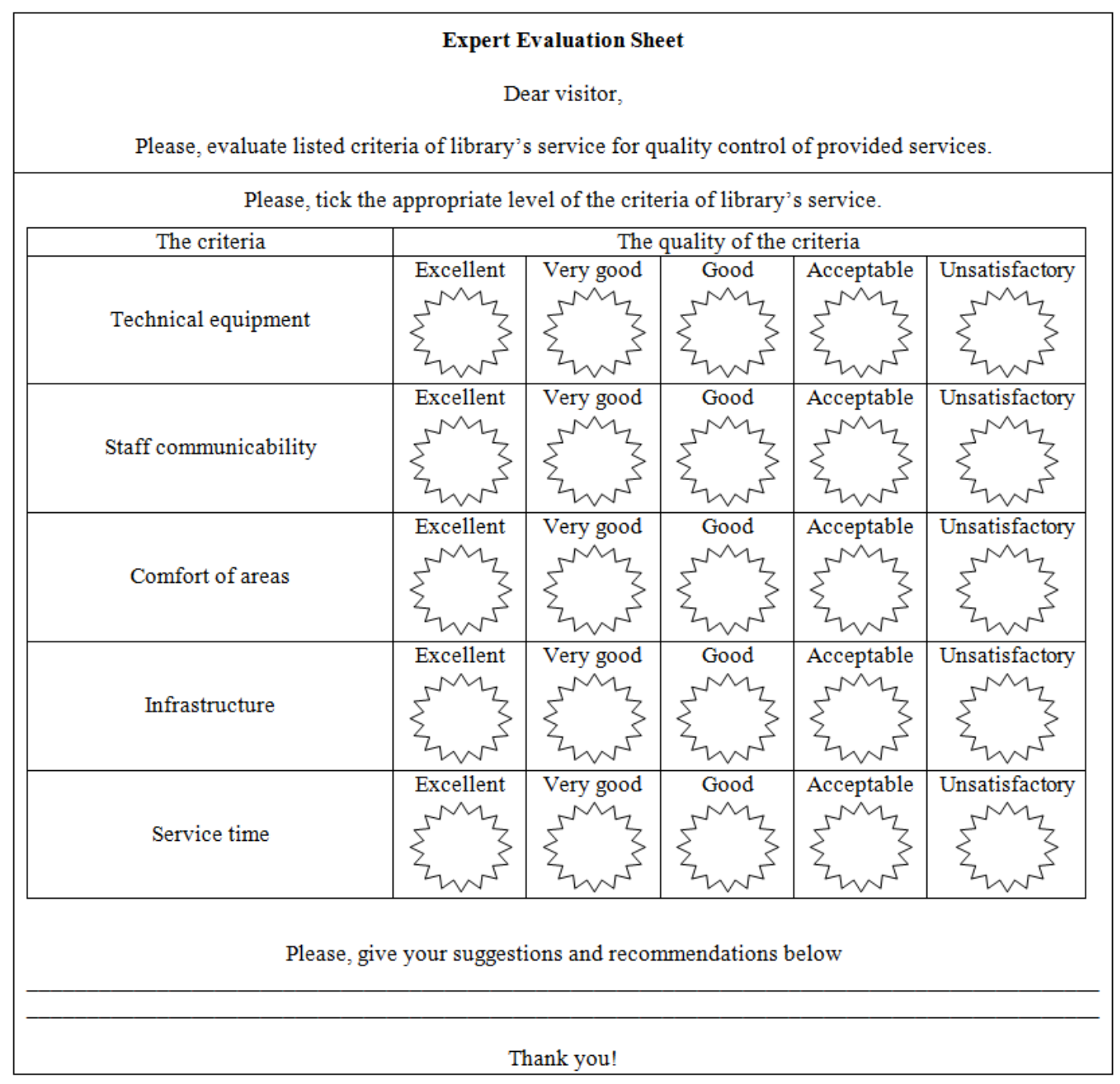

Fig. 2. Expert's evaluation sheet for library users. 
The results obtained in the survey conducted for a group of users of the Scientific-Technical Library, TPU (NTB TPU) and experts are the initial data for analysis. The primary information was presented in a non-numeric form; however, the respondent opinions were presented in the form of linguistic variables.

More than 80 respondents participated in the survey; about 50 questionnaires of these respondents were analysed in detail. Incorrectly completed questionnaires passed only the first processing stage. Among 50 participants of the survey, 9 respondents answered the questions via the Internet, 13 respondents responded by e-mail, the others filled in a paper version.

The study showed that $27.92 \%$ of the respondents attend the library weekly, $25.97 \%$ go to the library every month, $17.21 \%$ visit it every three months and $9.74 \%$ have never been to the library. As the opinions of the respondents are in the form of a linguistic variable, they should be transformed into numerical values. Appropriate conversions were carried out using the "Fuzzy Logic Toolbox" program.

The "Fuzzy Logic Toolbox" has a well-designed interface and allows design and diagnosis of fuzzy models. In addition, the "Fuzzy Logic Toolbox" provides the support of modern methods of fuzzy clustering and adaptive fuzzy neural networks. Graphical tools of the "Fuzzy Logic Toolbox" allow interactive tracking of the system behavior (Roghanian et al., 2015).

The $F_{1}$ and $\mathrm{F}_{2}$ efficiency indicators were chosen for the studied fuzzy logic system.

Figure 3 shows the input data of the $F_{1}$ efficiency indicator.

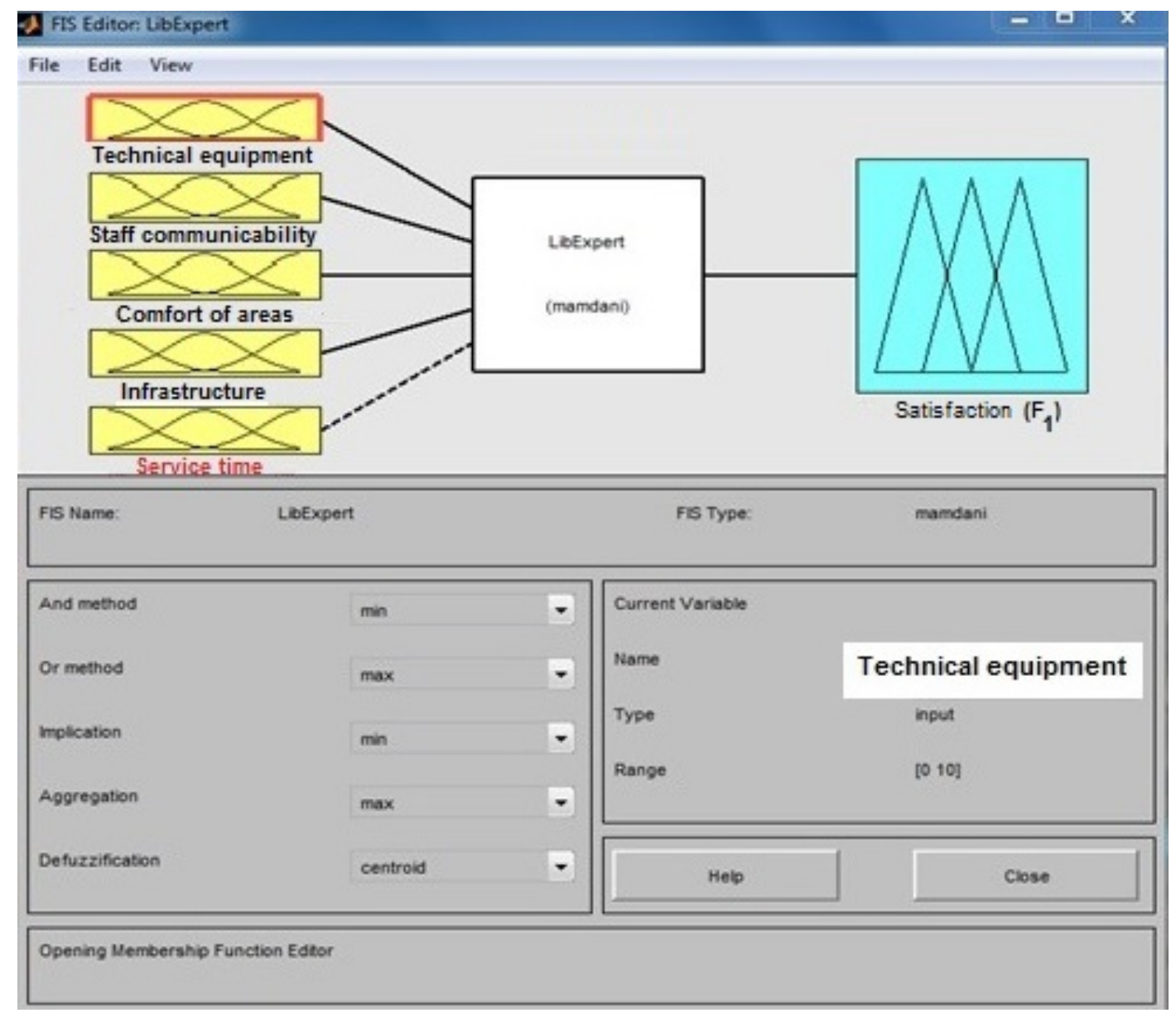

Fig.3. $F_{1}$ complex indicator of consumer satisfaction. 
A complex indicator of satisfaction by the research results, service and help provided for the questioned users has the following input data $\left(F_{1}\right)$ :

$>$ technical equipment of libraries, modernity and quality of software and materials;

$>$ staff friendliness and communicability (librarians, etc.) are defined by their attitude to the users;

$>$ library comfort (cleanliness, quality and comfort of the areas, presence of different media and communications with the outside world (Internet, print tools, stationary and mobile telephony, a dining room, places for sale, comfort of visitors, etc.);

$>$ infrastructure parameters: location, proximity to academic buildings, transport infrastructure, parking places, etc.;

$>$ time period of staying in the library and/or the time of queuing to get material (paper based or electronic version), waiting time of service provision, customer service time in the library after filling an application form.

The $F_{2}$ indicator of service quality and specialist qualification has the following input data:

$>$ popularity and qualification of the working staff;

$>$ volume and quality of advertising (in terms of value and efficiency of investments);

$>$ efficiency of the customer service (speed of query execution).

The logical inference algorithm (LibExpert) is used for transformation via the "Fuzzy Logic Toolbox" program. This algorithm specifies inputs and outputs, edits membership functions and rules, and displays the system surface.

A membership function for variables is set. The range of variable variation and display is set in the "Range" and "Display range" columns (from 0 to 10). The parameters of the intervals by the scale of the linguistic variable are specified in the "Params" column.

The values in this column are as follows: $L_{1}\left(F_{1}\right)$ is "unsatisfactory", $L_{2}\left(F_{1}\right)$ indicates "acceptable", $L_{3}\left(F_{1}\right)$ corresponds "good", $L_{4}\left(F_{1}\right)$ is "very good", $L_{5}\left(F_{1}\right)$ indicates "excellent".

Figure 4 shows the window of the function editor.

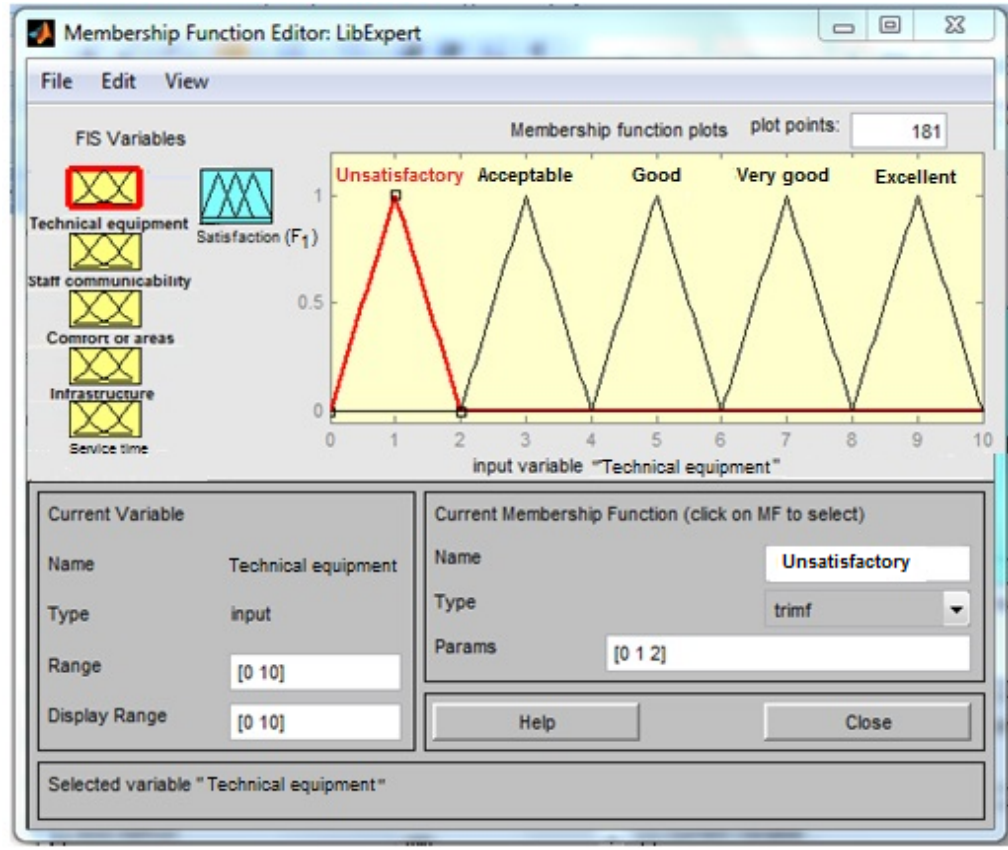

Fig. 4. Measuring ranges (F1) and fuzzy sets of different values of linguistic variables. 
The rules of different combinations are specified in the window of the function editor. The combination consists of the indicators from the linguistic scale. The input indicator "Technical equipment of the library, the modernity and quality of the software and materials" is assessed using the fuzzy logic by linguistic scale in the following way:

$L_{1}\left(F_{1}\right)$ "unsatisfactory" corresponds to numeric values from 0 to 2 ;

$L_{2}\left(F_{1}\right)$ "acceptable corresponds to numeric values from 2 to 4 ;

$L_{3}\left(F_{1}\right)$ "good" corresponds to numeric values from 4 to 6 ;

$L_{4}\left(F_{1}\right)$ "very good" corresponds to numeric values from 6 to 8 ;

$L_{5}\left(F_{1}\right)$ "excellent" corresponds to numeric values from 8 to 10 .

All the input factors are assessed similarly.

The questionnaire data concerning the $F_{2}$ indicator were processed.

Figure 5 shows the $F_{2}$ input data of efficiency indicator. Figure 6 shows the window of function editor of the $F_{2}$ indicator.

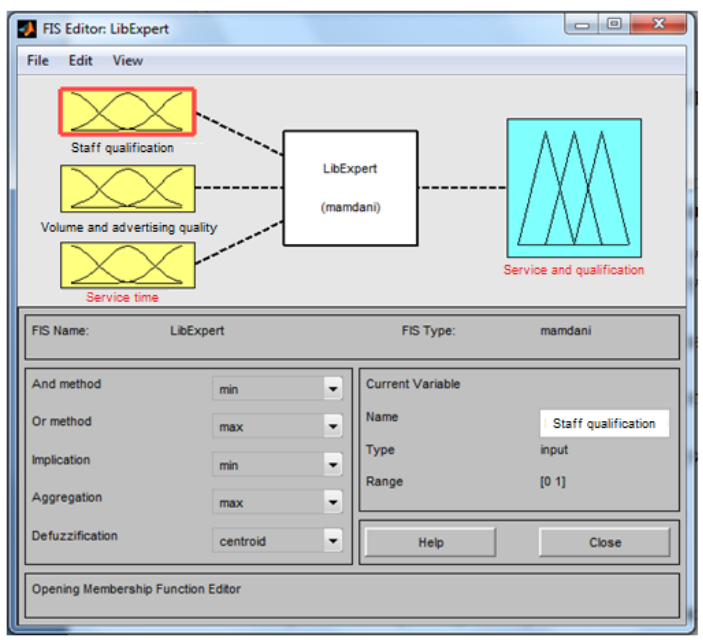

Fig. 5. $F_{2}$ complex indicator of service quality and qualification of the working staff.

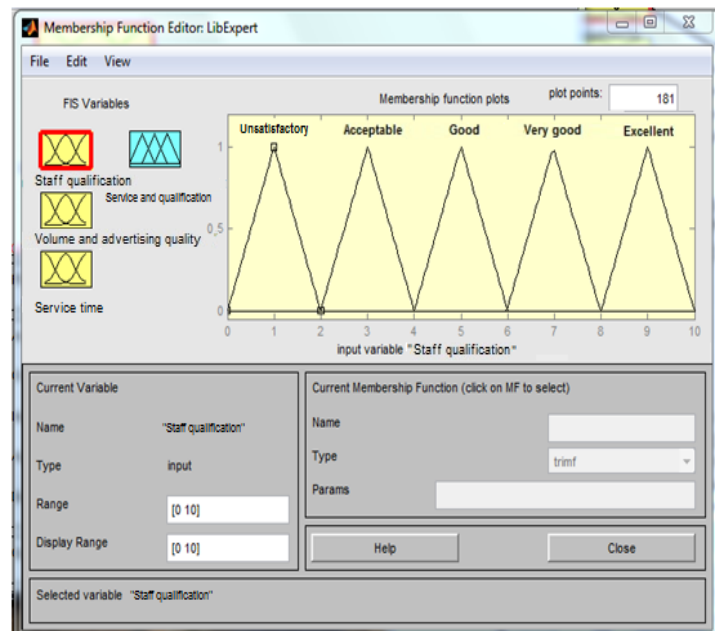

Fig. 6. Measuring ranges $\left(F_{2}\right)$ and fuzzy sets of different values of linguistic variables.

Rules editor window the F2 indicator is shown in figure 7.

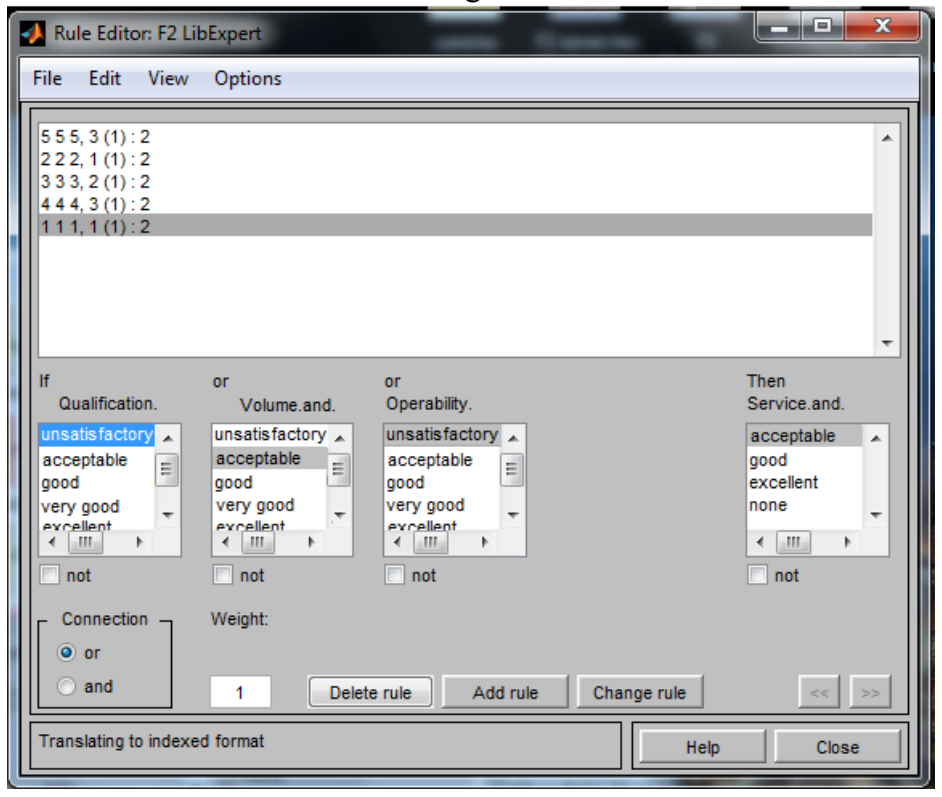

Fig. 7. Rules editor window of the F2 indicator. 
The values of the variables in numerical forms are obtained in result window with appropriate values. Necessary numerical value can be obtained at respective specified input parameters. Necessary numerical value can be received at the corresponding set input parameters.

Figure 8 shows result window.

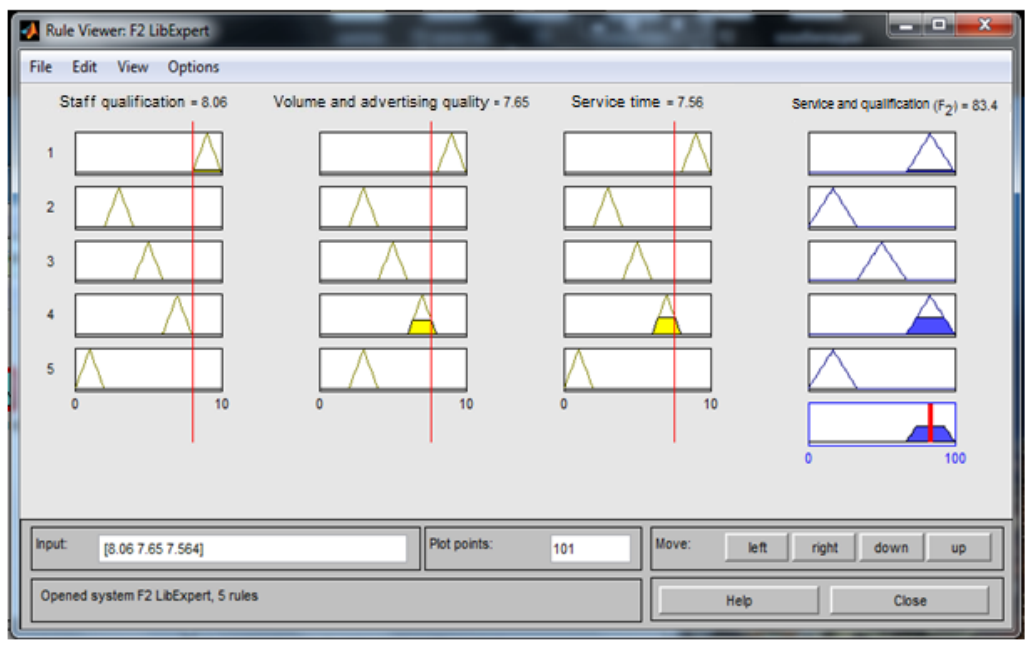

Fig. 8. Rules editor window.

The surface of the panel can be received at corresponding choice of menu item for display of dependence of output variable on input parameters.

Thus, "Fuzzy Logic Toolbox" allows using custom graphic interface to create fuzzy logic algorithms. Possibility of constructing fuzzy inference systems appears for creating of different expert systems. Blocks in "Simulink" allow creating controllers and control systems on fuzzy logic basis.

Questionnaires of 50 respondents have been treated in this program.

Table 1 shows results of our research.

Table 1. Results of evaluation of indicators of library activity.

\begin{tabular}{llll}
\hline \multirow{2}{*}{ Indicators } & Year & & \\
\cline { 2 - 4 } & 2013 & 2014 & 2015 \\
\hline$F_{1}, \%$ & 73 & 77 & 88 \\
$F_{2}, \%$ & 77 & 86 & 91 \\
\hline
\end{tabular}

The processed results were analysed and presented as graphs (see figures 9 and 10).

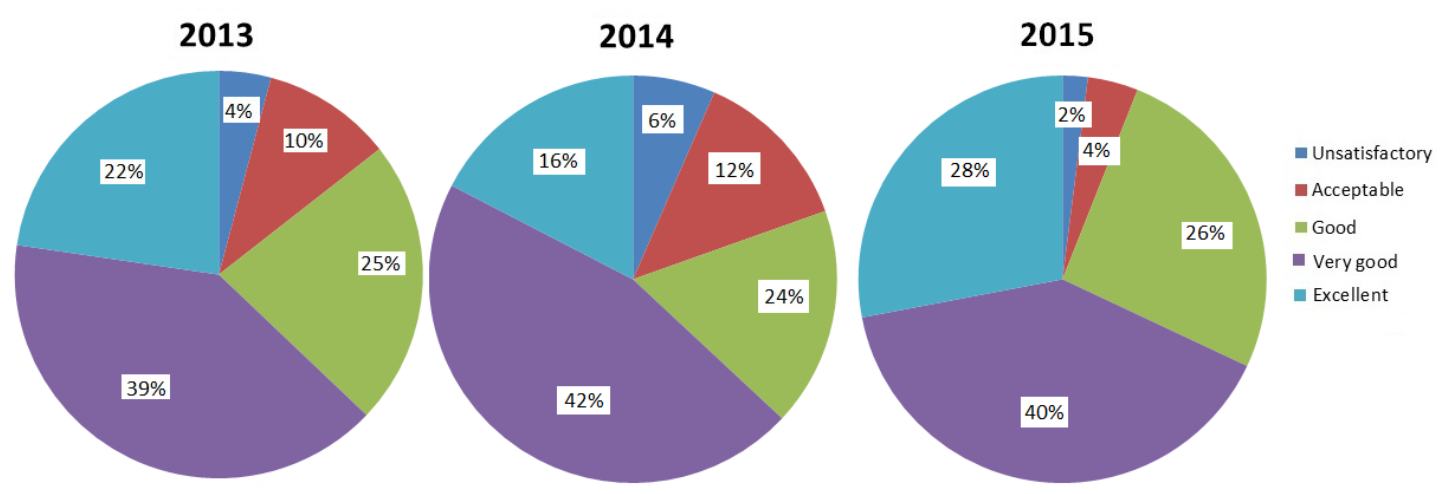


Fig. 9. Analysis results of the $F_{1}$ indicator.
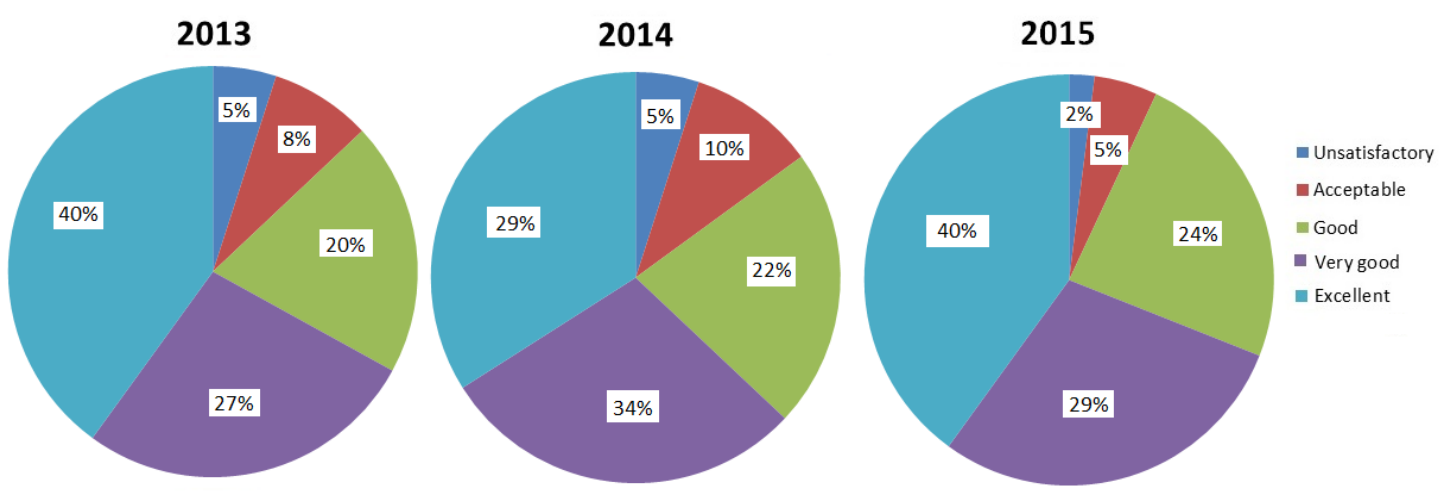

Fig. 10. Analysis results of the $F_{2}$ indicator.

\section{Conclusion}

The feature of this problem is that individual efficiency indicators and most of the input factors cannot be expressed in a quantitative form and submitted either in the form of values of linguistic variable or indicator of some rating scales.

Determining of significant factors and their quantitative influence on efficiency indicators and library services enhances the effectiveness of their work. It identifies the most urgent needs of the market, to determine correctly the further directions of investment and ways of improving the quality of service.

The results of these studies can be represented as regression dependences of every efficiency indicator from a set of factors, as well as in the form of ranked rows of these factors. These factors are arranged according to the degree of influence in specific conditions of library activities.

\section{References}

Alhumaidi, H. (2015). Multi-attribute fuzzy weighted average method to rank construction contractors. International Annual Conference of the American Society for Engineering Management, ASEM 2015; Indianapolis; United States, 31-41.

Campbell, J.T., Sirmon, D.G. \& Schijven, M. (2016). Fuzzy logic and the market: A configurational approach to investor perceptions of acquisition announcements. Academy of Management Journal, 59 (1), 163-187. doi: 10.5465/amj.2013.0663

Gong, J. \& Liu, L. (2010). Representing and measuring experts' knowledge based on knowledge network. Studies in Science of Science, 28(10), 1521-1530.

Lau, H.C.W., Nakandala, D., Zhao, L. \& Lai, I.K.W. (2015). Using fuzzy logic approach in estimating individual guest loyalty level for international tourist hotels, International Journal of Services, Technology and Management, 21 (1-3), 127-145. doi: 10.1504/IJSTM.2015.071097

Madhusudhan, M. \& Singh, V. (2016). Integrated library management systems: Comparative analysis of Koha, Libsys, NewGenLib, and Virtua. Electronic Library. 34 (2), 233-249. doi: 10.1108/EL-08-2014-0127

Natalinova, N., Rozhkova, O., Moldovanova, E., Ilina, N. \& Demin, N. (2016). Filtering for Stochastic Systems in the Case of Continuous Observation Channels with Memory of Arbitrary Multiplicity and Anomalous Noise International Siberian Conference on Control and Communications (SIBCON 2016), 1, doi: 10.1109/SIBCON.2016.7491866 
http://dx.doi.org/10.15405/epsbs.2017.01.65

eISSN: 2357-1330 / Corresponding Author: Nataliya Natalinova

Selection and peer-review under responsibility of the Organizing Committee of the conference

Roghanian, E., Moradinasab, N., Afruzi, E.N. \& Soofifard, R. (2015). Project risk management using fuzzy failure mode and effect analysis and fuzzy logic. International Journal of Services and Operations Management. 20 (2). 207-227. doi: 10.1504/IJSOM.2015.067477

Rogovyh, A. V., Natalinova, N. M., Spiridonova, A. S. \& Gordynets, A.S. (2015). Inspection Methods of LoadRecording Device "Gamma-500" International Siberian Conference on Control and Communications (SIBCON 2015), 1, doi: 10.1109/SIBCON.2015.7147190

Zimmermann H.-J. (2001). Fuzzy Set Theory and its Applications. Boston, Dordrecht, London: Kluver Academic Publishers. 